ISSN electrónico: 2172-9077

DOI: http://dx.doi.org/10.14201/fjc201612167182

\title{
ALFABETIZACiÓN CINEMATOGRÁFICA EN LAS AULAS. ATURUXO FILMS
}

\section{Media Literacy in the Classroom. Aturuxo Films}

\author{
Lic. Sergio CLAVERO IBÁÑEZ DE GARAYO \\ Profesor de Secundaria de Dibujo - IES de Cacheiras (Teo - A Coruña, España) \\ E-mail: aturuxofilms@gmail.com
}

(iD http://orcid.org/0000-0002-2069-4869

Fecha de recepción del artículo: 28/01/2016

Fecha de aceptación definitiva: 3/02/2016

\begin{abstract}
RESUMEN:
El presente artículo reflexiona sobre el eterno debate de la implantación en el sistema educativo de contenidos relacionados con la alfabetización audiovisual o cinematográfica. Y lo hace presentando un proyecto educativo desarrollado curricularmente en un centro de enseñanza secundaria denominado Aturuxo Films y que puede servir de referente para su desarrollo en otros centros educativos. Este proyecto ha sido reconocido, entre otros, con el Premio de Alfabetización Audiovisual 2014 del Ministerio de Educación, Cultura y Deporte del Gobierno de España.
\end{abstract}

Palabras clave: alfabetización audiovisual; ABP; creatividad; TIC.

\begin{abstract}
:
This article tackles the ongoing discussion on the implemetation of media literacy related contents into the education system. It introduces "Aturuxo Films", an educational project developed within a secondary school curriculum which may be used as a reference point by other learning centres. "Aturuxo Films" has been recognised, amongst others, by the Spanish Ministry of Education, Culture and Sports, which awarded it their Media Literacy Prize in 2014.
\end{abstract}

Keywords: Media literacy; PBI; Creativity; ICT.

\section{INTRODUCCIÓN}

La formación audiovisual y cómo implantarla curricularmente en los sistemas educativos está en permanente debate tanto en las instituciones españolas y europeas como en los organismos internacionales relacionados con la educación. Entre los expertos en pedagogía no existen dudas sobre la necesidad de formar a niños y jóvenes en un lenguaje que, desde hace décadas, aumenta su importancia en los ámbitos de la comunicación. El auge de las tecnologías de la información y de la comunica- 
ción y la implantación masiva de internet han facilitado no solo el acceso a los mensajes audiovisuales a través de múltiples pantallas, sino que nos han permitido convertirnos en productores que exhiben su obra en numerosas plataformas de la red. Surgen, por lo tanto, varias cuestiones a las que no se acaba de dar respuesta: ¿Cómo introducir su enseñanza en las aulas?, ¿`en qué etapas educativas? y ¿cuáles deben ser sus contenidos y su desarrollo curricular?

En este artículo se reflexiona sobre algunos de estos temas a través del análisis de una experiencia educativa denominada Aturuxo Films que introduce curricularmente la alfabetización cinematográfica en un instituto de enseñanza secundaria del municipio de Teo (A Coruña) desde el año 2007. Este proyecto, creado y coordinado por Sergio Clavero, profesor del propio centro IES de Cacheiras, ha recibido a lo largo de estos años numerosos reconocimientos, entre los que destaca el Premio de Alfabetización Audiovisual 2014 concedido por el Ministerio de Educación, Cultura y Deporte.

\section{AlFABETIZACIÓN CINEMATOGRÁFICA}

"Una comunidad alfabetizada es un colectivo dinámico, en el que se intercambian ideas y se suscitan debates" (UNESCO).

Los mensajes audiovisuales inundan los medios de comunicación, las redes sociales, las plataformas a las que accedemos de manera inmediata a través de los dispositivos móviles, tabletas y ordenadores y como expresa Juan Antonio Pérez Millán en Cine, enseñanza y enseñanza del cine:

[...] cualquier persona está hoy expuesta, desde su primera infancia, al influjo determinante de unos medios que se caracterizan, ante todo, por su inmediatez, su eficacia comunicativa, su atractivo para quien los contempla y su capacidad de penetración en todos los niveles de la personalidad individual y de los comportamientos colectivos. (Pérez Millán, 2014, p. 11).

En los últimos años se han desarrollado a nivel estatal y autonómico numerosos programas educativos que de alguna manera tratan el tema audiovisual y que se ofertan a los centros educativos bien de manera global o bien selectivamente. Estos programas, en unos casos, utilizan el cine como herramienta para debatir sobre diversos temas sociales como las drogas, la violencia, la igualdad... y, en otros, se plantean pequeños talleres de creación audiovisual muy limitados en el tiempo y donde la participación del alumnado difícilmente adquiere el protagonismo que requiere un proceso de aprendizaje convirtiéndose, en muchas ocasiones, en una actividad lúdica. En todos los casos se contemplan como una actividad complementaria o extraescolar ajena al currículum educativo.

Cuando se aborda esta alfabetización cinematográfica en los centros de enseñanza secundaria e incluso en el ámbito universitario se hace, habitualmente, desde un punto de vista analítico en una labor de análisis fílmico clásico y no desde el creativo como plantean Alain Bergala en La hipótesis del cine y Aturuxo Films en la metodología del proyecto.

Actualmente, y ante el requerimiento de la UE en su directiva europea sobre alfabetización mediática (Media Literacy) del 2007, estos contenidos se han introducido específicamente como parte del currículum de la materia de secundaria ahora denominada Educación Plástica, Visual y Audiovisual. Sin embargo, las limitaciones horarias y la cantidad y diversidad de contenidos a tratar en esta materia dificultan un desarrollo con la profundidad necesaria. Otro de los problemas es la escasa formación de gran parte del profesorado en esta área de conocimiento. 
Por lo tanto, se trata de un tema complejo que debe abordarse desde varios frentes y que no solo afecta a su introducción curricular (materias, carga lectiva...) sino a los objetivos que se quieren alcanzar, las metodologías para lograrlos y la formación específica del profesorado que debe impartir sus contenidos. Sin olvidar los medios asociados a las TIC, imprescindibles para su desarrollo. Estas y otras cuestiones se analizan a continuación a través del proyecto educativo Aturuxo Films.

\section{Aturuxo Films}

Bajo este título, a modo de productora, se enmarca el proyecto de alfabetización cinematográfica (o audiovisual) que engloba programaciones curriculares, proyectos audiovisuales, formación de profesorado y diversos blogs y recursos digitales.

Quizás es necesario empezar a pensar la película -aunque no es lo más fácil pedagógicamente- no como un objeto sino como la traza final de un proceso creativo, y el cine, como arte. Pensar la película como la traza de un gesto de creación. No como un objeto de lectura, descodificable, sino cada plano como la pincelada del pintor a través de la cual se puede comprender un poco su proceso de creación. (Bergala, 2007, p. 37)

Estas palabras de Alain Bergala, cineasta y profesor de cine en la Universidad de París III, en La bipótesis del cine expresan muy bien la filosofía de este proyecto que entiende todo el proceso de alfabetización que se describe a continuación como un acto de expresión creativa.

Figura 1. Logotipo de Aturuxo films.

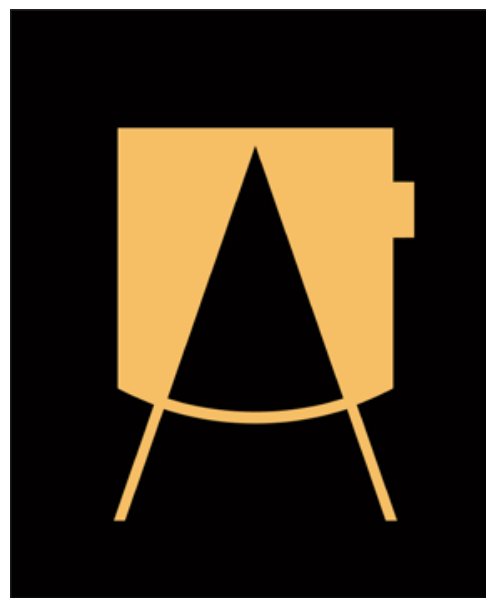

\subsection{Proyecto educativo}

Esta experiencia está basada en el desarrollo de la creatividad del alumnado con la producción de obras audiovisuales que fomenta el trabajo cooperativo y multidisciplinar con la participación de toda la comunidad educativa y la utilización de las herramientas TIC como elemento imprescindible para su desarrollo y difusión. Se trata de un aprendizaje basado en proyectos (ABP) donde el alumnado es un 
participante activo en la elaboración de conceptos y su posterior desarrollo a través de la experimentación. El objetivo es formar ciudadanos críticos adaptados a esta sociedad digital con una formación comunicativa y no solo instrumental o tecnológica.

Se implanta en el IES de Cacheiras (A Coruña) con la oferta de la materia optativa de centro Linguaxe audiovisual e medios dixitais en $3^{\circ}$ y $4^{\circ} \mathrm{ESO}$, Cultura Audiovisual en $1^{\circ}$ de bachillerato y en la materia Educación Plástica e Visual. A lo largo de los 9 años de aplicación de este proyecto se han matriculado en estas optativas específicas alrededor de 350 alumnos y alumnas del centro.

\subsection{OBJETIVOS}

Son varios los objetivos importantes que persigue un proyecto de alfabetización, por un lado, los relativos a las funciones comunicativas del propio lenguaje, como el conocimiento de los principios básicos de la sintaxis cinematográfica para producir e interpretar mensajes a través de su análisis. Por otro, los relacionados con el desarrollo de capacidades como el pensamiento creativo para elaborar nuevas ideas o con las metodologías donde se fomenta el trabajo cooperativo como elemento de integración entre el alumnado para aprender a escuchar, exponer y dialogar con respeto, cooperación y flexibilidad, desarrollando un espíritu crítico constructivo. También impulsa la resolución de problemas, planificando y organizando las actividades y el tiempo de forma efectiva. Otro de los importantes objetivos es aprender a emplear las tecnologías de la información y la comunicación como herramientas que nos permiten acceder, evaluar, crear y comunicar, ética y legalmente participando activamente en la sociedad del conocimiento. Por lo tanto utilizar las TIC como un medio que facilita los procesos creativos.

\subsection{Metodología}

La metodología utilizada parte de un aprendizaje basado en proyectos (ABP) donde el alumnado trabaja de manera autónoma constituyendo grupos de trabajo para el desarrollo de su propio conocimiento. Todo el proceso de creación de una obra audiovisual se realiza a través de un trabajo colaborativo del alumnado donde las herramientas TIC dan soporte y facilitan la producción. Los integrantes de cada grupo de trabajo investigan, intercambian información y debaten para alcanzar acuerdos durante todo el proceso creativo, desde la idea inicial y el desarrollo del guión hasta el rodaje y la edición. Esta metodología activa les ayuda a resolver problemas, a mejorar su capacidad de trabajo en equipo y a desarrollar capacidades mentales. Las herramientas TIC les ayudan a construir mejores relaciones de trabajo y facilitan el proceso creativo y la consecución del producto final: la obra audiovisual. Deben estar diseñadas para mejorar las habilidades de investigación y la capacidad de análisis, para crear una comunidad de trabajo colaborativo a través de plataformas virtuales con las que intercambian información y avanzan el proyecto fuera del horario lectivo y para facilitar el desarrollo de la producción de la obra y así alcanzar el éxito a través de la experimentación y el ensayo error. El docente durante todo este proceso facilita información, recursos y asesoría generando momentos de aprendizaje a través de diferentes reuniones de trabajo.

\subsubsection{Cine, Cultura y Educación}

\section{Sintaxis.}

El proceso de alfabetización se inicia con la explicación de los fundamentos de la sintaxis cinematográfica a través de ejemplos gráficos y fílmicos de grandes películas de la historia del cine. De esta 
forma se divulgan los movimientos artísticos desarrollados a lo largo del tiempo y las aportaciones de directores, actores y actrices, compositores, directores de fotografía...

Figura 2. Presentación contenidos sintaxis cinematográfica.

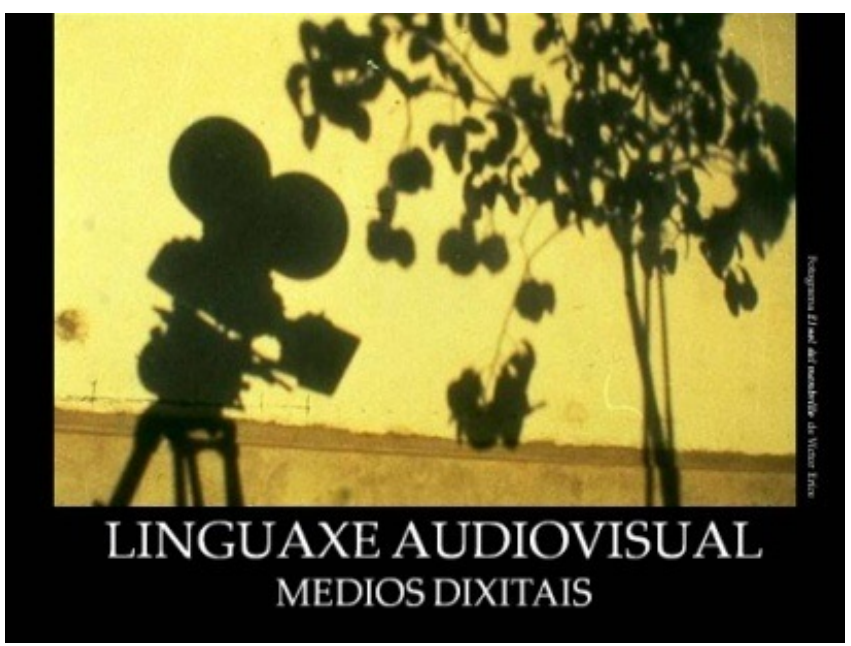

Es importante formar a los nuevos espectadores para que conozcan y sepan apreciar también el cine que se encuentra fuera de las grandes multinacionales de distribución y exhibición. En el aula se proyectan fragmentos de grandes películas y se fomenta el visionado de buen cine a través de la videoteca que todo el alumnado tiene a su disposición en la biblioteca donde se cuida la selección de las adquisiciones cinematográficas.

Figura 3. Proyección en el aula de los contenidos de la sintaxis cinematográfica.

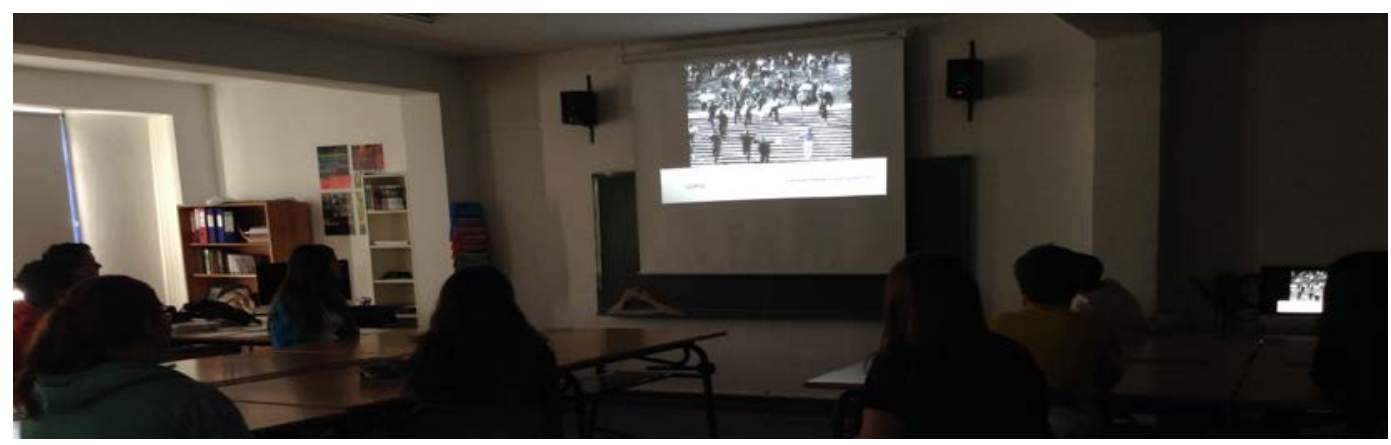

\section{Análisis}

Para abordar el análisis cinematográfico y audiovisual debemos situarnos desde el punto de vista de la creación, es decir, como un análisis de las opciones formales y expresivas elegidas por el director 
para narrar, expresar y emocionar y que permitirán al alumnado comprender en qué consiste el acto creativo y las posibilidades que ofrecen los elementos sintácticos. Alain Bergala en su libro La hipótesis del cine expresa muy bien esta idea:

El análisis de creación, contrariamente el análisis fílmico clásico cuya única finalidad es comprender, descifrar, leer la película como se dice en la escuela- prepararía o iniciaría para la práctica de la creación. (Bergala, 2007, p. 127).

Figura 4. Proyección en el aula de Alumbramiento de Víctor Erice.

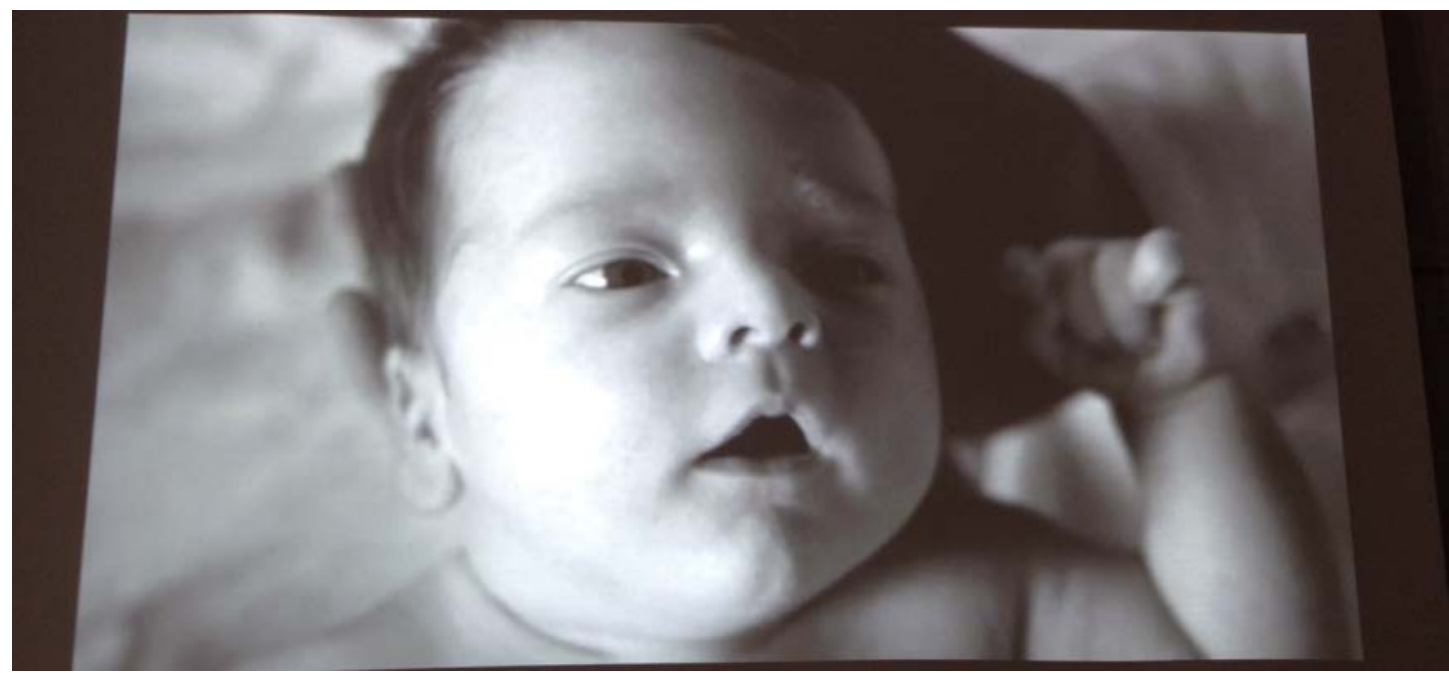

Para ello se utilizan fragmentos de películas o cortometrajes de grandes directores, como Alumbramiento, de Víctor Erice, que permite descubrir al alumnado, tras su visionado y debate, la utilización de los recursos formales y expresivos, las metáforas visuales, la simbología y fundamentalmente descubrir, en parte, el proceso creativo que ha dado lugar a esa obra.

El tema de la publicidad también es muy interesante como elemento de análisis por su brevedad e intenciones claras. Tras una introducción a los mecanismos que utiliza la publicidad para conseguir la venta y el consumo de un producto el alumnado reflexiona, en la mayoría de los casos por primera vez, sobre la engañosa realidad que nos muestra la publicidad en televisión. Con este objetivo se analiza con una mirada escrutadora y crítica un spot televisivo a través de unas fichas que están estructuradas para una recogida de datos formales y una interpretación posterior de esos contenidos formales y expresivos.

Tras la reflexión individual se realiza la puesta en común que enriquece el debate y ayuda a llegar a algunas conclusiones. A partir de este momento el alumnado dice ver los anuncios publicitarios con una mirada más crítica y consciente que se hace extensible al resto de contenidos audiovisuales, tanto de televisión como de la red.

\subsubsection{Procesos Creativos y TIC}


Tras los conocimientos previos de los fundamentos de la sintaxis y el análisis realizado que nos permite entender las decisiones formales, expresivas y artísticas tomadas por sus creadores es el momento de que el alumnado pase por su propia experiencia de creación audiovisual. Es en este proceso donde se produce el verdadero aprendizaje a través de la investigación, la experimentación y la toma de decisiones en un trabajo de equipo donde se distribuyen las diferentes funciones. Esto permite que el alumnado pueda descubrir y desarrollar sus diferentes cualidades y expresarse con actividades distintas a las habituales en el ámbito escolar.

Dentro de esta metodología activa de aprendizaje el alumnado utiliza una plataforma virtual de trabajo colaborativo para trabajar desde casa a través de conversaciones y tareas asignadas y compartir archivos como el guion, la lista de sonidos, localizaciones, etc. Esto permite que todo el proceso avance sin tener que estar en el aula, como en fines de semana y vacaciones. En el aula comparten, debaten y organizan las tareas.

Es interesante que previamente al trabajo en equipo realicen alguna pequeña actividad de creación individual que les permita descubrir la responsabilidad de la toma de decisiones para el desarrollo de ideas, la elección de los recursos sintácticos o la producción final de la obra audiovisual.

Para explicar el proceso creativo que se desarrolla en la fase experimental de alfabetización audiovisual de Aturuxo Films vamos a ejemplificarlo con la producción del cortometraje Persoas, creado por alumnado de $4^{\circ} \mathrm{ESO}$ en la materia optativa Linguaxe audiovisual e medios dixitais.

Figura 5. Cartel y sinopsis PERSOAS.

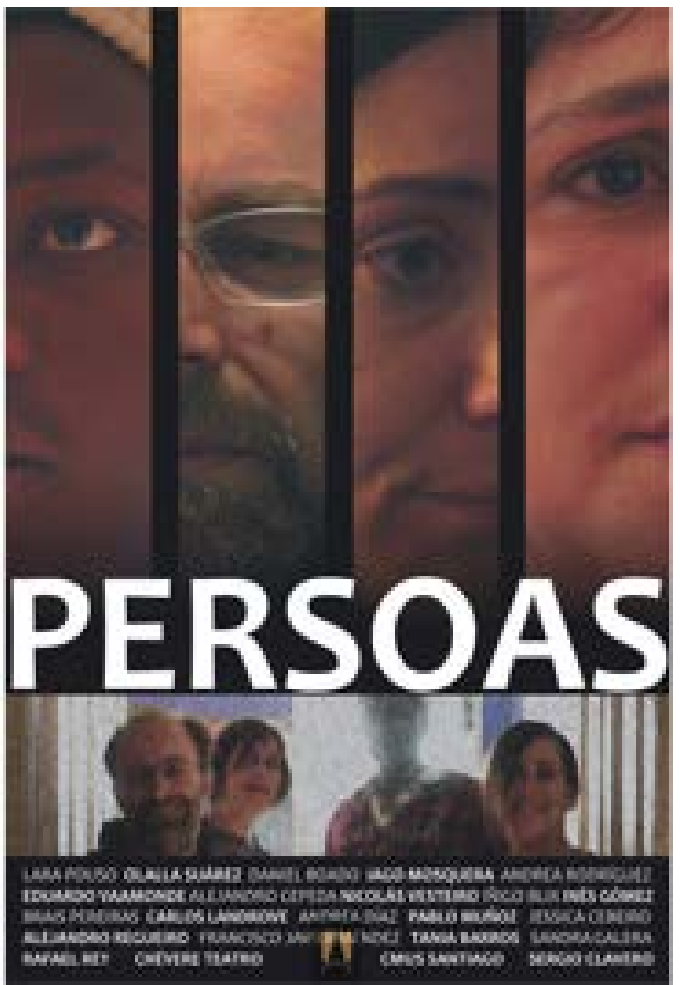

(C) Ediciones Universidad de Salamanca / CC BY - NC ND Fonseca, Journal of Communication, n. 12, 2016, pp. 167-182 


\section{SINOPSIS}

Historias de cuatro personas que por diferentes motivos se ven obligadas a emigrar. Coinciden en un piso de acogida donde muestran los conflictos personales.

El proceso de trabajo se desarrolla con una estructura similar a la del cine profesional pero adaptando la complejidad de la propuesta a la tipología de alumnado, a los medios disponibles y, sobre todo, a la temporalización del proyecto. Realizan todo el proceso propio de la creación cinematográfica tanto en la preproducción con el desarrollo de la idea hasta el guion, como en la producción con el rodaje y la postproducción con el montaje de imágenes y sonidos. Es fundamental que aprendan a organizarse y a planificarse para lograr el objetivo común participando colectivamente del proceso y llevando a cabo cada una de sus funciones con responsabilidad y autonomía.

Durante todo este proceso el profesor está atento a la planificación, el desarrollo de los diferentes proyectos y la resolución de dudas y problemas que vayan surgiendo. Además amplia información y realiza un seguimiento de los avances convocando reuniones periódicas con cada grupo así como con los responsables de las diversas funciones asignadas.

Las obras creadas van desde spots con contenido social, pasando por la ficción y el documental, hasta el videoarte donde se desarrolla toda la expresividad de las imágenes y los sonidos.

\section{PREPRODUCCIÓN}

En esta fase se organizan los diferentes grupos de entre 3 y 5 integrantes -en función de la propuesta- que desarrollarán todo el proceso creativo. Cada uno de ellos tiene una función específica, desde la más creativa hasta la más técnica. De manera colectiva se plantea la propuesta inicial de trabajo.

Figura 6. Grupo de alumnado debatiendo el guion de Persoas.

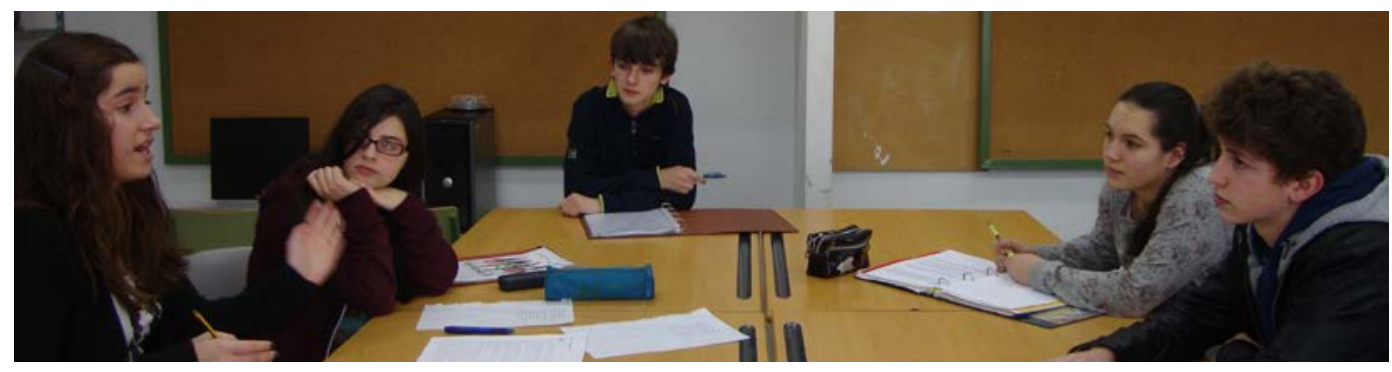

Se inicia aquí un trabajo individual de documentación a través de las TIC que facilitan el acceso a una información que deben aprender a seleccionar, analizar y sintetizar. Cada integrante expone sus ideas maduradas durante la documentación al resto del grupo, que reflexiona y debate para seleccionar el tema y el enfoque que se le va a dar. 
En el caso del cortometraje PERSOAS el argumento inicial parte de una obra de teatro escrita por el alumno Rafael Rey de $4^{\circ}$ ESO para el programa COMENIUS L'Europe en six actes en el que participa el IES de Cacheiras. Partiendo de un mismo argumento se realizaron la obra teatral PERSON$N E$ y desarrollaron el guion del corto PERSOAS.

Figura 7. Representación de Personne en Marsella.

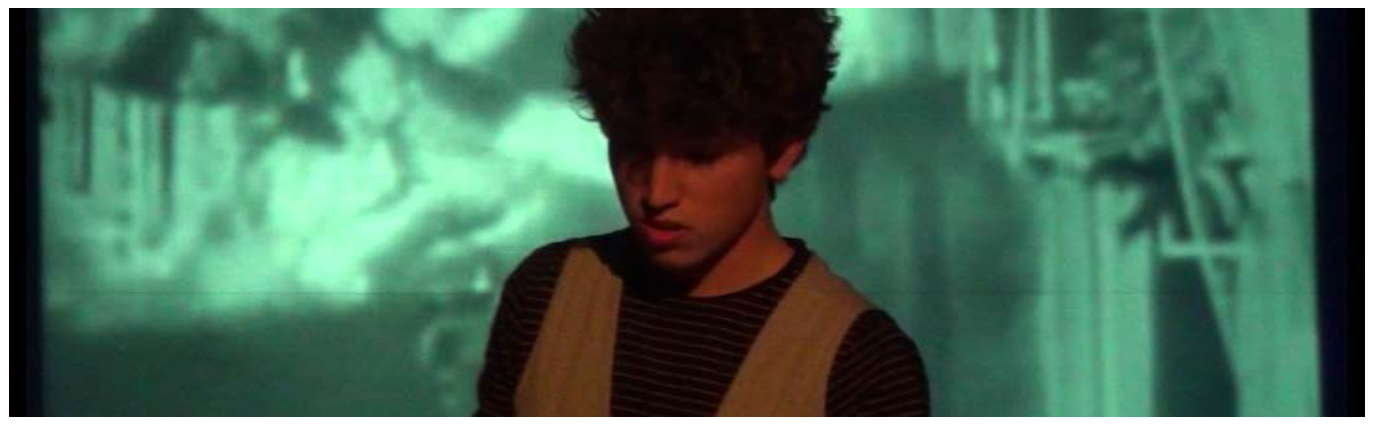

Tabla 1. Relación de personajes y conflictos que representan en PERSOAS

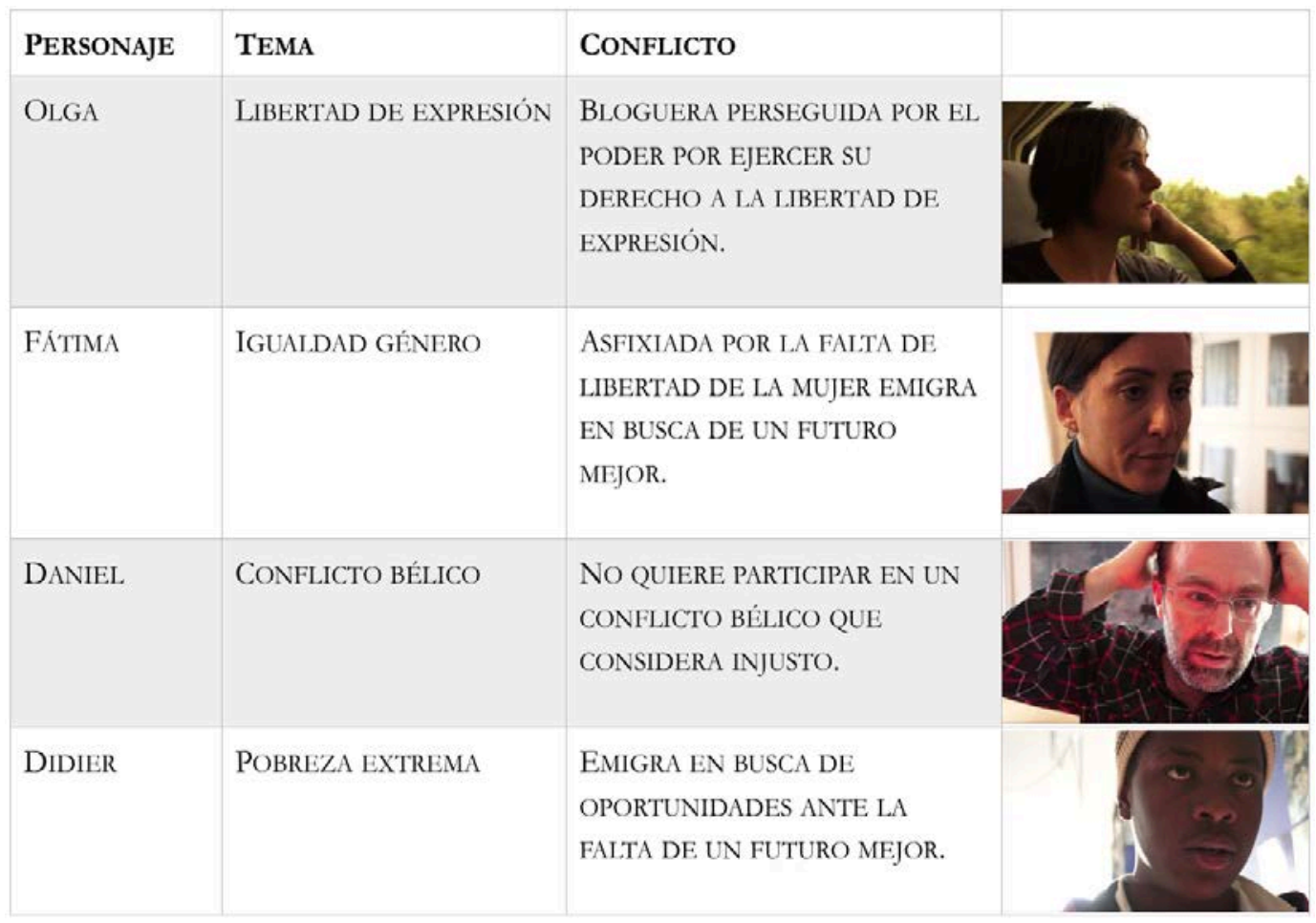


El alumnado se organiza para desempeñar las distintas funciones una vez que han sido establecidas las bases del argumento entre todo el grupo.

Tabla 2. Cargos y funciones a desempeñar en el grupo de trabajo en la preproducción.

\begin{tabular}{|l|l|l}
\hline PRODUCTOR & - Casting para los personajes de la obra. \\
& - Localizaciones. \\
& - Preparativos previos y necesidades de material. \\
& - Plan de rodaje. \\
\hline DIRECTOR/A & - Desarrollo del guion y storyboard. \\
\hline GUIONISTA & - Desarrollo del guion y storyboard. \\
\hline FOTOGRAFÍA & - Prácticas de cámara. \\
\hline EDICIÓN & - Ensayos con actores y actrices. \\
\hline & - Prácticas con software de edición. \\
\hline
\end{tabular}

Durante esta fase se realiza un seguimiento, sobre todo, del desarrollo del guion a través de diferentes reuniones con sus responsables en las que se debaten y sugieren nuevas ideas.

Los encargados de la producción realizan un casting entre los propios alumnos/as y, en este caso, contactaron con el grupo teatral Chévere, Premio Nacional de Teatro 2014, afincado en el municipio, para interpretar los papeles protagonistas.

También realizan las localizaciones buscando los lugares donde grabar las diferentes escenas creando un reportaje fotográfico de los espacios y diferentes puntos de vista.

La información gráfica obtenida en las localizaciones se utiliza para la creación del storyboard. En este proyecto educativo se considera muy importante su realización, ya que permite al alumnado reflexionar sobre las intenciones narrativas y expresivas de cada escena del guion y la manera de trasladarlas, utilizando los recursos sintácticos del lenguaje cinematográfico, a imágenes y sonidos. Este espacio de reflexión enriquece a su vez el propio guion en una búsqueda constante por expresar la idea inicial. En el lugar de rodaje este documento deberá ser modificado en función de las condiciones de luz, los espacios, los puntos de vista más adecuados o para solucionar aquellos problemas que surjan y, siempre, para trasladar las emociones al espectador con una buena puesta en escena.

Mientras el guion va cobrando forma tanto el director/a de fotografía como el técnico de edición realizan prácticas para explorar fundamentos de composición, iluminación y enfoque en el caso del primero y de expresión, ritmo y narración en el caso del segundo.

\section{PRODUCCIÓN}

El rodaje se realiza habitualmente fuera de las instalaciones del centro, bien en casas particulares o bien en espacios exteriores localizados por el propio alumnado. Este se enfrenta al rodaje sin la presencia del profesor para no condicionar su trabajo. Posteriormente el grupo junto con el profesor debaten sobre la organización del rodaje y el material obtenido con el objetivo de corregir errores. Como en todo el proceso creativo se debate sobre lo previamente realizado por el alumnado. La experiencia adquirida les permite mejorar las siguientes sesiones de rodaje tanto desde el punto de vista organizativo como desde el punto de vista técnico y expresivo para alcanzar lo previsto en el guión. 
Tabla 3. Cargos y funciones a desempeñar en el grupo de trabajo en la producción.

\begin{tabular}{|c|c|}
\hline PRODUCTOR & $\begin{array}{l}\text { - Se encarga de la organización, de los preparativos y nece- } \\
\text { sidades de material durante el rodaje (vestuario, ilumina- } \\
\text { ción y atezo. }\end{array}$ \\
\hline DIRECTOR/A & - Dirección. \\
\hline GUIONISTA & - $\quad$ Claqueta y script. Racord. \\
\hline FOTOGRAFÍA & - $\quad$ Encuadres, iluminación y grabación. \\
\hline TÉCNICO DE SONIDO & - Micrófono. \\
\hline
\end{tabular}

Lo más complicado fue organizar las diferentes agendas de los actores y actrices de Chévere y el rodaje se realizó en seis tardes. En este caso sí acudió el profesor para controlar el cumplimiento del plan de rodaje, dada la implicación del grupo teatral.

Figura 9. Rodaje de Persoas.

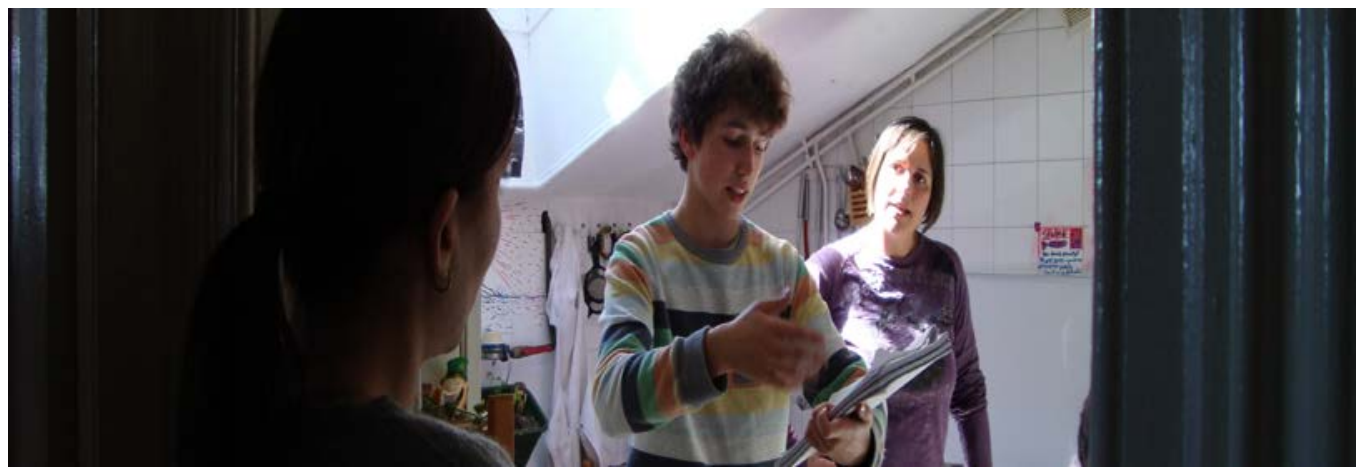

Figura 10. Rodaje de Persoas.

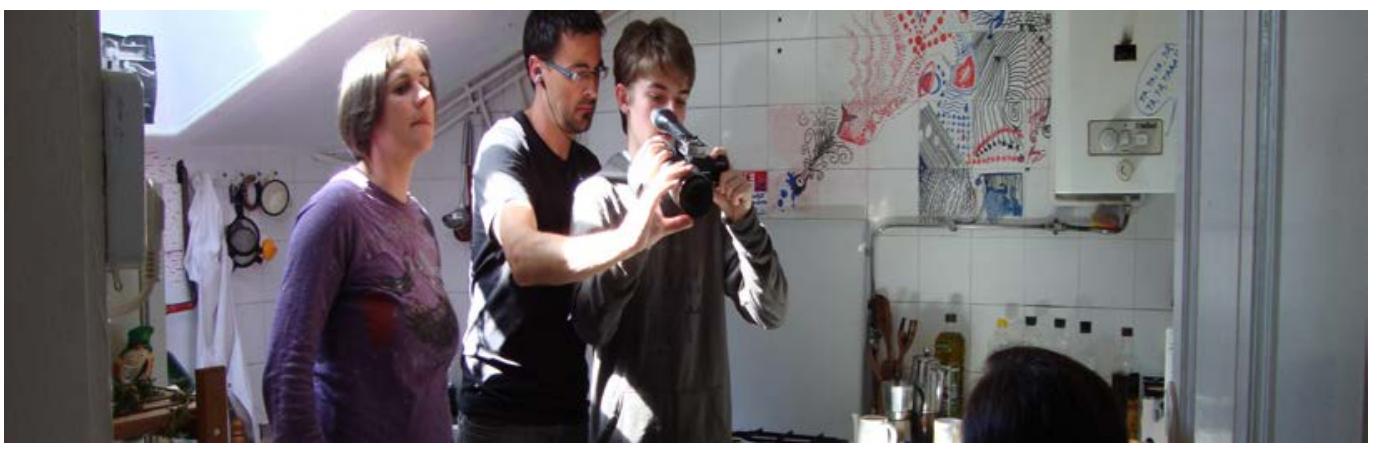




\section{POSTPRODUCCIÓN}

En la edición comienza a verse el fruto del trabajo en equipo. Cuando esta avanza el profesor analiza con el alumnado el resultado obtenido para profundizar en los conceptos relacionados con esta. Se prepara, así mismo, el diseño gráfico para la promoción y exhibición de la película.

Tabla 4. Cargos y funciones a desempeñar en el grupo de trabajo en la postproducción.

\begin{tabular}{|c|l|l|}
\hline PRODUCTOR & - & Volcado al PC. \\
\hline DIRECTOR/A & - & Organización de las necesidades que surjan. \\
\hline GUIONISTA & - & Edición de imagen y sonido. \\
\hline FOTOGRAFÍA & - & Creación «Títulos de crédito». \\
& - Diseño de cartel y carátula DVD. \\
\hline EDICIÓN & - Manejo técnico de edición. \\
\hline
\end{tabular}

Parte de los integrantes del grupo se dedicó a dar forma definitiva al cortometraje en la edición. Para crear los ambientes sonoros se utilizaron archivos del Instituto de Tecnologías Educativas del Ministerio de Educación.

Figura 11. Montaje de Persoas.

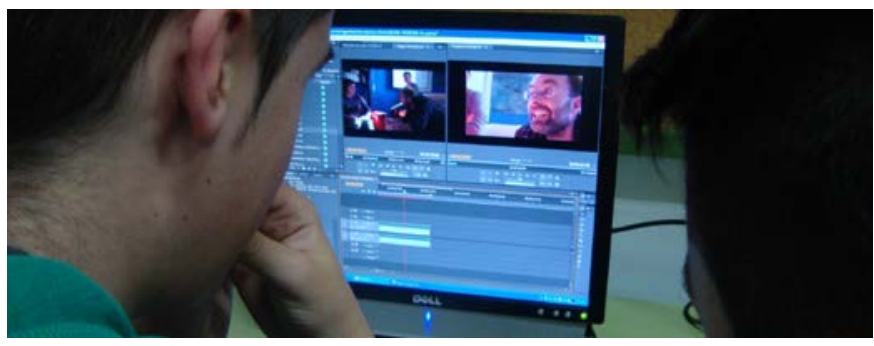

Figuras 12 y 13. Fotogramas de Persoas.
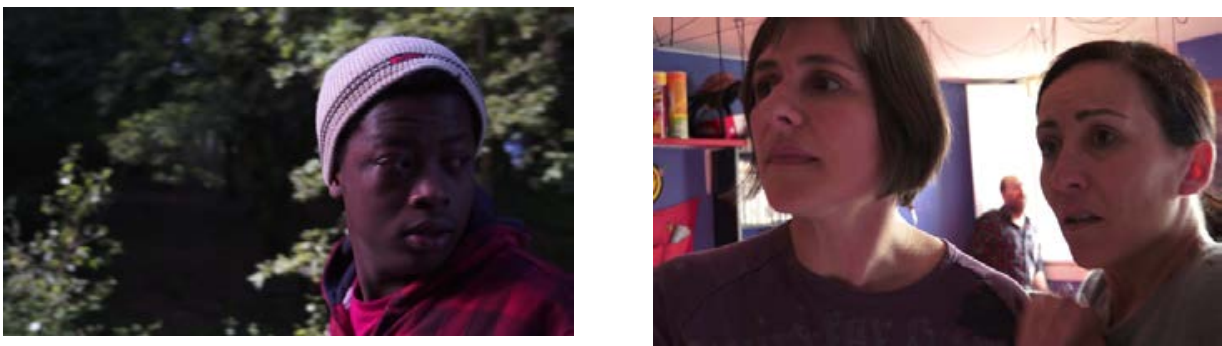

(C) Ediciones Universidad de Salamanca / CC BY - NC ND Fonseca, Journal of Communication, n. 12, 2016, pp. 167-182 


\section{COMPOSICIÓN MÚSICA}

Uno de los elementos de una obra cinematográfica que se descuidan habitualmente en el ámbito educativo es, además de la creación de los ambientes sonoros, la música. Por eso el IES de Cacheiras y el Conservatorio Profesional de Música de Santiago de Compostela han suscrito un acuerdo de colaboración para que alumnado de este último centro componga e interprete la música de las obras audiovisuales del proyecto educativo Aturuxo Films.

Fruto de esta colaboración es la composición por parte de Sandra Galera, alumna del CMUS de Santiago y ex-alumna del IES Cacheiras, de la banda sonora del corto Persoas. La interpretación instrumental fue realizada por alumnado del CMUS: clarinetes, piano, guitarras y percusión.

Figura 14. Grabación en el Conservatorio profesional de música de Santiago de Compostela.

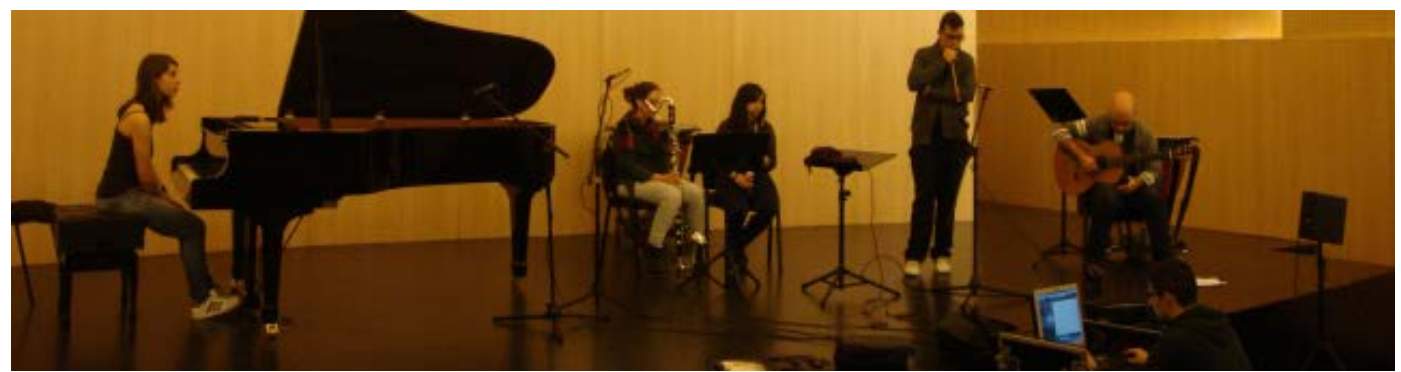

En la actualidad se desarrollan varios proyectos de colaboración y, además de bandas sonoras para las obras audiovisuales, se avanza en uno nuevo donde la música compuesta por alumnado del conservatorio, desde contemporánea, a jazz o electrónica, sugerirá las imágenes al alumnado del centro de secundaria. De esta forma colaboran en procesos de creación conjuntos.

\section{EXHIBICIÓN}

Para cerrar el acto comunicativo que supone la creación audiovisual debemos llegar a los espectadores a través de la exhibición presentando la obra audiovisual como fruto de la experiencia educativa y del proceso creativo. Es importante que el alumnado creador pueda exponer ante la comunidad educativa sus logros.

A modo de ejemplo, en los años 2013 y 2014 hemos participado en los siguientes festivales y certámenes de cine: CINEMA JOVE DE VALENCLA, TIMELINE FILM FESTIVAL DE MILÁN, OUFF ESCOLA DE OURENSE, PRIMAVERA DE CINE DE VIGO, OLLOBOI DE GALICIA E INTERNATIONAL YOUTH FILM FESTIVAL DE PLASENCIA.

El estreno de PERSOAS se ha realizado en el Concello de TEO y en el Centro Galego de Arte Contemporánea de Santiago de Compostela donde están situados el IES de Cacheiras y el Conservatorio Profesional de Música respectivamente. En este acto, tras la proyección del cortometraje, se ha establecido un coloquio entre el alumnado que lo ha producido y el público con el objetivo pedagógico de divulgar el proceso creativo. 


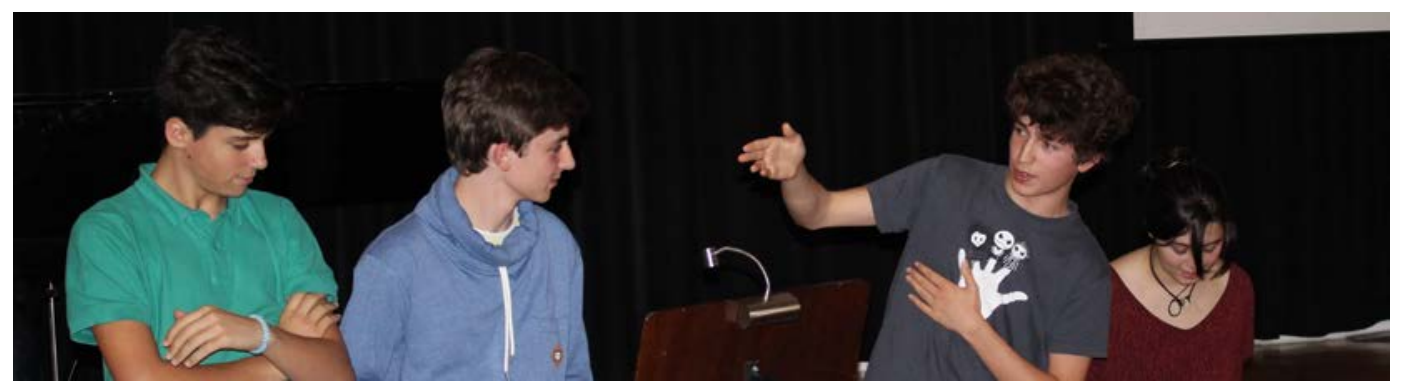

Otro canal de divulgación del proceso de producción del cortometraje es el blog de aula $C A$ DERNO DE RODAXE que quiere servir de guía para profesorado y alumnado con interés por desarrollar un proyecto educativo de alfabetización audiovisual.

Figura 16. Blog de aula que desvela el proceso creativo de Persoas.

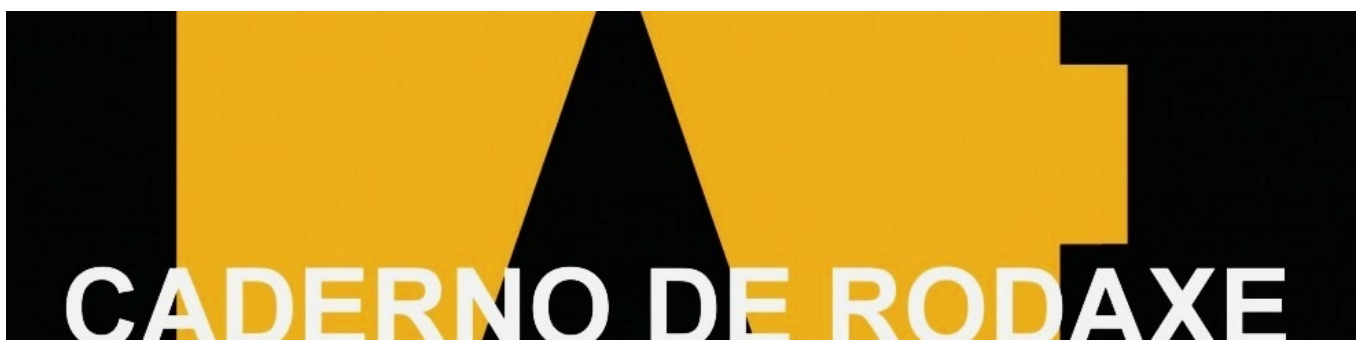

En la red se pueden visionar muchas de las obras creadas en este proyecto educativo en el CANAL YOUTUBE ATURUXO FILMS.

\subsection{Procesos de EVAluación}

Este proceso de creación y trabajo en grupo es el eje central del proyecto aprendiendo a utilizar las TIC como un medio imprescindible para alcanzar un objetivo claro, la obra audiovisual. Sin embargo, lo importante es el propio proceso y que el alumnado sea el responsable de su propia experiencia de aprendizaje, sea cual sea el resultado.

Se establece una relación con el alumnado más horizontal donde la capacidad de organización de los miembros del grupo y las responsabilidades que asumen les permiten demostrar que son capaces de alcanzar el objetivo después de un largo e intenso periodo de trabajo. Es muy importante basar la relación entre profesor y alumnado y entre ellos mismos en la confianza, la responsabilidad y el respeto. Aprenden a utilizar las TIC como herramientas para crear un mensaje audiovisual de manera eficaz y responsable y que la búsqueda de información a través de internet debe hacerse atendiendo a las fuentes y a una selección lógica. 
A lo largo del proceso de aprendizaje se realizan varias evaluaciones por parte del alumnado. La primera de ellas al final del análisis publicitario donde ponen de manifiesto de manera explícita su sorpresa por los mensajes asociados que les llegan inconscientemente en un anuncio televisivo y destacan que este aprendizaje ha cambiado por completo la manera en la que miran la televisión. En segundo lugar realizan una autoevaluación del funcionamiento del grupo a lo largo del proceso de creación de la obra audiovisual. Valoran, asimismo, el trabajo y las aportaciones de cada miembro para el logro del objetivo final. En este apartado cabe destacar las dificultades que dicen tener para lograr una implicación similar en todos los componentes. Consideran necesario aprender a escuchar más y ser más responsable con el trabajo personal en beneficio de todos. El alumnado valora positivamente el desarrollo del proyecto y el nivel de aprendizaje alcanzado pero, sobre todo, que se les permita trabajar en grupo y de una forma más práctica utilizando las TIC.

\subsection{INCIDENCIA SOCIAL Y CULTURAL}

Otro de los objetivos del proyecto es fomentar la educación en valores a través de las temáticas que abordan las diferentes obras audiovisuales. Estas, a su vez, se convierten en un recurso muy importante para divulgar contenidos sociales contribuyendo a la compresión y el enriquecimiento con diferentes realidades, reconociendo la igualdad de derechos entre distintos colectivos. A lo largo de estos años se han abordado temas como el acoso escolar, la igualdad de género, la educación para la paz, la sostenibilidad, la violencia de género, el cuidado del medio ambiente, las libertades y la convivencia... a través de spots sociales, documentales u obras de ficción.

En PERSOAS se trata el tema de las migraciones centrándose en los sentimientos, las emociones y las dificultades de las personas. Los conflictos que aborda nos invitan también a reflexionar sobre la violencia, la libertad de expresión, las desigualdades económicas y la igualdad de género en las sociedades actuales.

Se están elaborando unidades didácticas para el uso de estas obras audiovisuales como material para abordar en el aula temas sociales.

Otra característica del proyecto es su apertura hacia otros organismos e instituciones públicas que complementan y enriquecen el aprendizaje del alumnado. La creación cinematográfica como acto cultural y artístico debe ser un puente de colaboración con el entorno social, cultural e institucional y en el caso de Aturuxo films se plasma, además de en el Conservatorio de Música de Santiago de Compostela, en el Concello de Teo, asociaciones de ámbito social, la Universidad trasladando el proyecto a los futuros profesores o entidades culturales del entorno.

\section{ConCLusiones}

En este proyecto se plantea la necesidad de que la alfabetización cinematográfica se desarrolle curricularmente desde la experimentación para que los diversos contenidos se asimilen a través de un aprendizaje ligado a las emociones de los procesos creativos. Las programaciones no deben recoger una simple enumeración de conceptos y un recorrido histórico lleno de datos y fechas sino un lenguaje que sirve de herramienta para desarrollar el pensamiento creativo, la colaboración y la solidaridad, que nos forma en valores y nos permite conocer mejor la realidad social y cultural. Porque los centros de enseñanza deben ser espacios culturales donde el alumnado tenga la oportunidad de acceder al denominado cine de autor y a lo más representativo de la historia del cine para poder definir sus gustos personales y formar a los nuevos espectadores. 
Como educadores debemos descubrir el potencial del alumnado con metodologías más activas y una estructura de contenidos y actividades perfectamente diseñada para un aprendizaje profundo y eficaz. Para ello es necesario una adecuada formación del profesorado tanto en los contenidos relacionados con el lenguaje cinematográfico como en las metodologías más apropiadas para que el alumnado experimente en un proceso de creación que deje huella en su aprendizaje.

\section{BIBLIOGRAFÍA}

Bergala, A. (2007). La hipótesis del cine. Pequeño tratado sobre la transmisión del cine en la escuela y fuera de ella. Barcelona: Laertes.

Pérez Millán, J. A. (2014). Cine, enseñanza y enseñanz̧a del cine. Madrid: Ediciones Morata.

Arnheim, R. (1996). El cine como arte. Barcelona: Paidós.

Bazin, A. (1991): ¿Qué es el cine? Madrid: Rialp.

Dondis, D. A. (2002). La sintaxis de la imagen. Introducción al alfabeto visual. Barcelona: Gustavo Gili.

Eisenstein, S. (1989). Teoría y técnicas cinematográficas. Madrid: Rialp

Galeana, L. (2007). Aprendizaje basado en proyectos. Universidad de Colima.

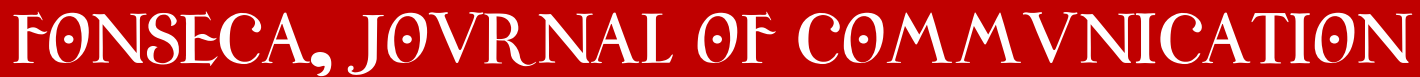

